\title{
The association between tobacco plain packaging and Quitline calls
}

TO THE EDITOR: Young and colleagues report that the introduction of plain tobacco packaging led to a sharp increase in calls to the New South Wales Quitline service, reaching a 78\% relative increase after 4 weeks, with a sustained, projected impact over 43 weeks. ${ }^{1}$ Their study illustrates, first, the immediate benefits that governments can expect when legislating for larger graphic warnings and a standardised display of tobacco brand information in plain packaging.

Second, the study by Young and colleagues shows that it is vital for governments to adopt a "learning by doing" approach, ${ }^{2}$ trialling new, regulatory strategies for reducing risk factors for costly and preventable diseases that complement educative and social marketing strategies. If governments insist on cast iron proof of impact for new interventions that have not yet been trialled, progress will grind to a halt. The path to longer and healthier lives requires innovation, refined by rigorous evaluation and ongoing monitoring of net effects.

Third, this study illustrates how the tobacco industry has become a useful "canary in the mineshaft", through its predictable, vociferous opposition to policies that are likely to be effective. In the words of one tobacco industry spokesperson:

We believe that there's actually no proof that [plain tobacco packaging] is going to work and in the end it could end up costing taxpayers billions of dollars. ${ }^{3}$

But if plain tobacco packaging will not achieve its goal of reducing smoking, why would the industry spend shareholders' money on a doomed High Court challenge? ${ }^{4}$ Why the national advertising campaign conceived by Imperial Tobacco Australia featuring "nanny" — that public health advocates will remember with delight for many years to come (see https:// www.youtube.com/watch?v= Zlho9i4dgXs)? 
Plain tobacco packaging legislation is great news for public health, and also, let's not forget, a credit to Australian parliamentarians.

Roger S Magnusson Professor

Sydney Law School, University of Sydney, Sydney, NSW. roger.magnusson@sydney.edu.au

Competing interests: No relevant disclosures. doi: 10.5694/mjal4.00065

1 Young J, Stacey I, Dobbins T, et al. The association between tobacco plain packaging and Quitlinecalls: a population-based, interrupted time series analysis. Med J Aust 2014; 200: 29-32.

2 Australian Government Preventative Health Taskforce. Australia: the healthiest country by 2020. Discussion paper. Canberra: Preventative Health Taskforce, 2008: 92. http://www. preventative health.org.au/internet/preventativehealth/ publishing.nsf/Content/discussion-healthiest (accessed Mar 2014).

3 Mclntyre S, spokesperson for British American Tobacco Australasia. Plain packaging will cost taxpayers: BATA. ABC News, uploaded 7 A pril 2011. http://www.youtube.com/watch?v= wEXH7mqEEWE (accessed Jan 2014).

4 JT International SA v Commonwealth of Australia (2012) HCA 43 (5 October 2012).

IN REPLY: We thank Magnusson for placing our study ${ }^{1}$ in the broader context of government involvement in public health initiatives. A key point that deserves further exploration is the role of governments around the world when novel legislative initiatives are introduced to improve the health of the population. Each government that introduces novel laws or regulations must also ensure that it has adequate resources to measure the impact of these measures. If this is not done, there is the risk of failing to fully quantify the impact of the new initiatives.

The three studies published to date that evaluate aspects of the impact of introducing plain tobacco packaging were not funded by the jurisdiction that introduced the legislation. ${ }^{1-3}$ It is notable that our study would not have been possible without ongoing investment in long-term longitudinal data collection that enabled the comparisons between different initiatives (the introduction of graphic health warnings and the introduction of plain packaging) to be undertaken.

Jane M Young Professor in Cancer Epidemiology'

David Currow Chief Executive Officer ${ }^{2}$

Sally Dunlop Research Associate ${ }^{2}$

1 Cancer Epidemiology and Services Research (CESR), Sydney School of Public Health, University of Sydney, Sydney, NSW.

2 Cancer Institute NSW, Sydney, NSW.

jyoung@email.cs.nsw.gov.au

Competing interests: No relevant disclosures.

doi: 10.5694/mjal4.00191
1 Young J, Stacey I, Dobbins T, et al. The association between tobacco plain packaging and Quitline calls: a population-based, interrupted time series analysis. Med J Aust 2014; 200: 29-32.

2 Wakefield MA, Hayes L, Durkin S, et al. Introduction effects of the Australian plain packaging policy on adult smokers: a cross-sectional study. BMJ Open 2013; 3: e0031753.

3 Zacher M, Bayly M, Brennan E, et al. Personal tobacco pack display before and after the introduction of plain packaging with larger pictorial health warnings in Australia: an observational study of outdoor caféstrips. Addiction 2014; 109: 653-662. doi:10.1111/add.12466. 